Orr, J. B. (1937). Food, Health and Income, and. ed. London: Macmillan \& Co. Ltd.

Registrar-General (1938). Decennial Supplement, Part II a, England and Wales, 1931. London: H.M. Stationery Office.

Tappen, N. C. (1950). Amer. F. phys. Anthrop. 8, 49.

Witts, L. J. (1947a). Brit. med. $\mathcal{F}$. i, 1.

Witts, L. J. (1947b). Brit. med. $\mathcal{\jmath} . \dot{i}, 45$.

\title{
Phases of Postnatal Growth
}

\section{By R. W. B. Elurs, Department of Child Life and Health, University of Edinburgh}

The development of the human young from birth to maturity can be divided arbitrarily into a series of stages each characterized by peculiarities of physiology, nutritional requirements, physical proportions, and social adaptation. Whilst it may be convenient to refer to these phases in terms of chronological age, there is a considerable physiological variation between individual children and between the two sexes in the age at which each successive stage is reached and passed. These individual differences become more obvious clinically in the later age groups, but substantial developmental differences in osseous development can be demonstrated radiologically even amongst groups of normal infants and pre-school children of the same age. Mean standards of bone age or osseous development have been established by Todd (1937) and Greulich \& Pyle (1950) for children of both sexes from birth to the age of 18 years and are valuable in assessing the developmental age of a particular child.

\section{Methods of assessment}

It is the purpose of the present communication to outline briefly the phases of postnatal growth which may be recognized, and to show that these do not bear a consistent relationship to chronological age. Whilst it is not intended to discuss in detail the various methods that have been adopted to assess and analyse growth, it will be realized that our present knowledge has been built up in two ways, the 'cross-sectional' study of large numbers in each age group, and the 'longitudinal' or continued study of the same individuals over a period of years. The methods used in assessing the individual child have evolved from the crude comparison of individual height and weight with mean values obtained from the examination of large numbers of healthy children in each age group. A significant advance was made by the construction of weight-heightage tables for pre-school children (Woodbury, r92I) and schoolchildren (Baldwin \& Wood, 1923) in which the necessity for correlating height with weight was clearly recognized. Subsequently height and weight indices (Sutcliffe \& Canham, 1950) and percentile ratings have been employed with the purpose of indicating the child's relationship to the mean and to the normal range in each age group, and it has been found that the child tends to retain his position within the group in relation to any particular measurement during childhood (Meredith, 1937a,b). At the present time, the most satisfactory method of recording individual growth in childhood is probably the Wetzel grid (Wetzel, 1943). From this graphic record in which height and weight 
are correlated it is possible to see whether the child's progress falls within the expected channel for age and sex, and deviations from the height-weight relationship characteristic of children of particular body-build become obvious. The methods of assessing growth and progress in infancy are rather less satisfactory than for schoolchildren, partly owing to the greater difficulties of accurate measurement. The fallacies of adopting weight as the sole criterion, and of comparing the individual infant's weight curve with a composite weight curve are so obvious that they should not require emphasis if they were not so frequently overlooked and so often responsible for unnecessary anxiety. 'Thus the birth weights of healthy full-term infants may vary by more than $100 \%$, and this variation in birth weight is likely to be reflected to some extent in the weight curve subsequently. Indeed, Illingworth, Harvey \& Gin (1949) have shown that in each age group from 6.5 to 13 years, children of higher birth weight are on the average significantly heavier and taller than those of lower birth weight.

\section{Phases of postnatal growth and development}

The neonatal period, arbitrarily taken as the ist month of life, during which the infant is adapting to extra-uterine existence. During the first 4 or more days the infant commonly loses weight, the loss depending to some extent on the birth weight, establishment of lactation, capacity for vigorous sucking, and other factors. 'The birth weight is usually regained by the roth day.

Early infancy, or the suckling period preceding the eruption of the first teeth, the lower central incisors usually appearing at approximately 6 months of age. This period is marked by rapid growth, the birth weight of ten being doubled, or more than doubled, by the age of 6 months. This is reflected in the high caloric requirement of $50 \mathrm{Cal} . / \mathrm{lb}$., compared with the estimated figure of $20 \mathrm{Cal} . / \mathrm{lb}$. for an adult working male.

Later infancy, from 6 months to 2 years of age, during which the eruption of the first dentition is completed, the diet is gradually enlarged by the addition of solids from one almost exclusively of milk, and the acquisition of speech and upright posture involves a corresponding enlargement of physical and intellectual horizon.

The fourth or 'pre-school' period is one demarcating by social custom in this country the ages 2-5 years, though developmentally it would be better if extended to 6 or 7 years, to correspond both with the eruption of the second dentition and to changes in physique which are observable clinically. Whilst the home remains the central nidus of culture and infection, the pre-school child is extending his social contacts with the consequent likelihood of contracting the common infections of early childhood from outside sources. New skills and more systematized play techniques are rapidly acquired, with corresponding effects on intellectual and muscular development.

Childhood proper, lasting from the age of 6 or 7 years to the onset of puberty. During this period the major part of the second dentition is established. In the emotional development of the child this period is sometimes described as 'latent', whilst physical growth in general tends to be relatively slow and uniform until the onset of puberty is approached. 'The period is, however, associated with an acceleration in growth of lymphoid tissue, and failure to recognize the physiological nature of tonsillar enlargement in childhood may lead to unnecessary tonsillectomy. 
Pubescence, which may be defined as the period beginning with the earliest evidence of either genital development or appearance of secondary sexual characters such as pigmented pubic hair, or breast development in girls, and ending with the menarche (first menstruation) in girls, and with advanced and uniform genital development in boys. It has been estimated that pubescence lasts approximately $1 \cdot 2$ years in boys reaching pubescence at 13.5 years, and approximately 2.5 years when pubescence begins at 10.5 or at 14.5 years (Ellis, 1948a); for girls, the figures given by Hogben, Waterhouse \& Hogben (1948) indicate an average duration of pubescence (onset of breast development to menarche) of $2 \cdot 6$ years. Girls were also found to show onset of pubescence 2-2.5 years earlier than boys (Cawley, Waterhouse \& Hogben, 1949).
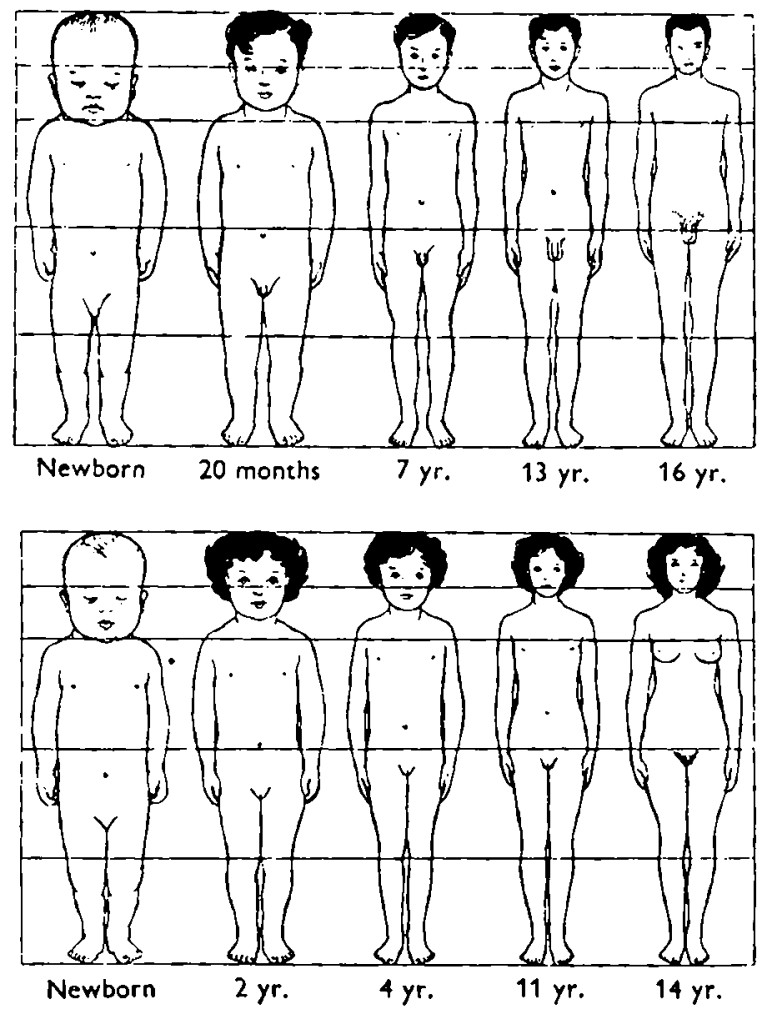

Fig. x. Proportions from birth to adolescence (Ellis 1947).

Adolescence is the period immediately following pubescence and culminating in fusion of the epiphyses of the long bones with consequent cessation of growth. In a large-scale study of children and adolescents, Simmons (1944) found that terminal height might be reached as early as 15 or as late as 20 years in boys, and in girls as early as 14 or as late as 18 years.

\section{Physical proportions}

The relative physical proportions of each of these earlier phases of development are best illustrated diagrammatically (Fig. I). It will be seen that in the newborn infant the head represents approximately one-quarter of the total length and the legs approxi- 
mately three-eighths. The abdomen and trunk are relatively large and the limbs short. In adolescence, in contrast, the head represents only one-seventh of the total length and the legs one-half. The proportions have changed from the brevilinear ones of infancy to the longilinear ones characteristic of early adolescence, whilst the umbilicus has risen from well below the midline to well above it.

In addition to the changes in skeletal growth revealed by external measurement or radiography, there are characteristic differences in the rate of growth of different tissues (Scammon, 1930). The growth of nervous tissue is most rapid during the first 2 years and minimal after the age of 8 years; the growth of lymphoid tissue is maximal during middle and later childhood; whilst the growth of the gonads after the 2nd year is minimal until the onset of pubescence, when it shows rapid acceleration. The rate of mental growth has not been found to show any close correlation with the abrupt changes in rate of skeletal growth associated with increasing maturity (Abernethy, 1936).

\section{Sexual maturation}

The period of sexual maturation requires special consideration by those concerned with the nutrition and health of the schoolchild, since rapid acceleration in growth is likely to be reflected in changes in appetite and nutritional requirement. A number of the more detailed growth studies have been carried out on girls and related to the onset of menstruation (e.g. Shuttleworth, 1937, 1938) since, although the first menstruation does not necessarily correspond with onset of ovulation and is commonly followed by a period of relative sterility, it provides an easily defined point in time which may be taken to indicate the beginning of adolescence. It has been found that whilst there are certain differences in growth pattern between groups of girls reaching the menarche early or late, there is in general a maximum increment in standing height during the 1 or 2 years preceding the menarche, followed by rapid deceleration in height increment until terminal height is reached. 'This is well illustrated by Shuttleworth's (1937) method of superimposing the growth curves of groups of girls menstruating at different ages or of groups in which the maximum annual growth increment occurred at different ages. By plotting the growth-curves of the various groups so that the age of menarche falls in the same vertical line, it becomes obvious that the growth pattern relates more closely to puberty than it does to chronological age.

Since the pre-adolescent spurt of growth is related to the menarche, it is necessary to emphasize the wide variation in age at which the first menstruation may occur. Thus in a series of $47^{\circ}$ healthy English women age of menarche was found to vary from 9.5 to 18 years, and in a smaller Nigerian series from 11.5 to 17.5 years. In both instances the distribution curves showing the percentage reaching the menarche in each year of age (Fig. 2) were of approximately similar shape, though the mean of age of menarche in the English series was 13.7 years and that in the Nigerian series 14.2 years, giving no support to the popular view that puberty occurs earlier in the tropics than in temperate zones. Other English figures comparable to those quoted are given by Wilson \& Sutherland (1949) and Hogben et al. (1948). With boys, it is possible to recognize with reasonable accuracy three successive stages of maturity, which I have described as non-pubescent, pubescent, and adolescent, on clinical criteria which have 
Vol. 5

been detailed elsewhere (Ellis, 1946). Owing to the difficulty in classifying certain borderline cases, these three gradings have been used in preference to the five described by Greulich, Dorfman, Catchpole, Solomon \& Culotta (1942), whilst the criterion of

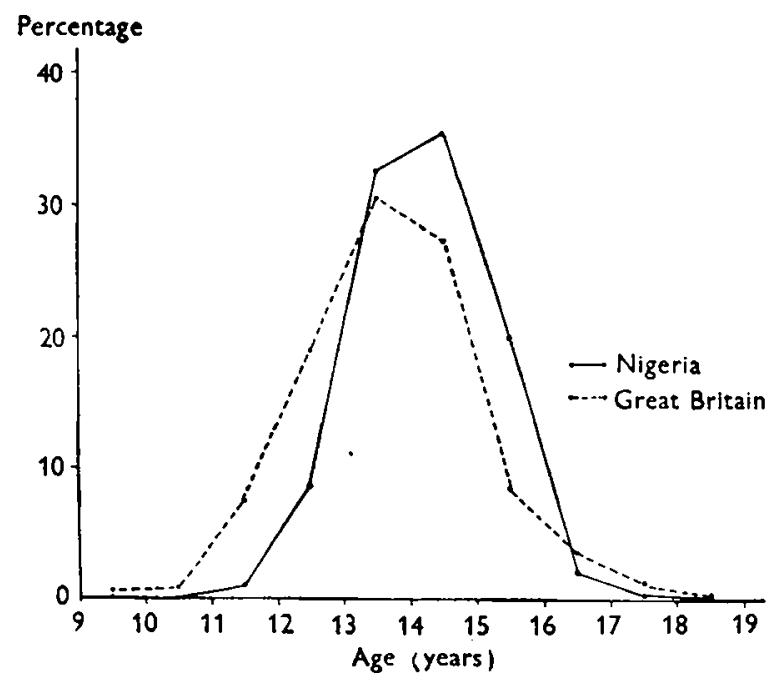

|Fig. 2. Percentage of girls reaching the menarche in each year of age, Nigeria and Great Britain (Ellis, I 950).

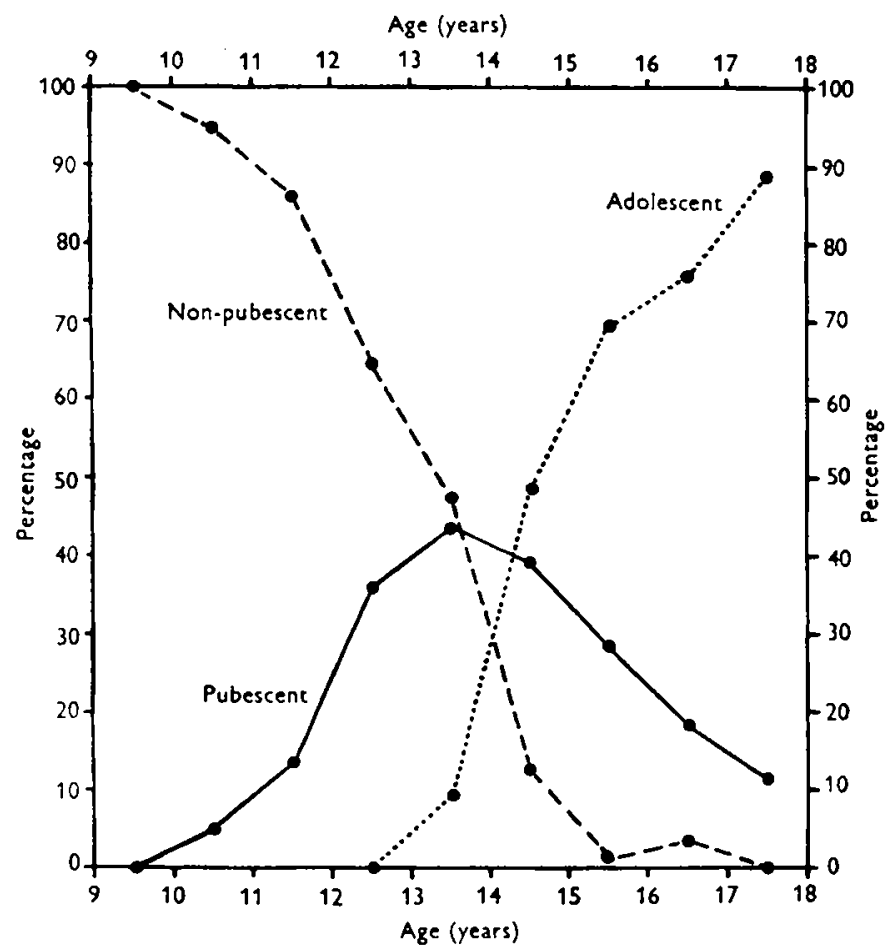

Fig. 3. Percentage of boys graded as non-pubescent, pubescent and adolescent in each year of age (Ellis, 1946). 
adolescence used by Richey (1937), namely appearance of axillary hair, has been felt to be inadequate. By applying this maturity grading to boys between 9 and $\mathrm{I} 8$ years of age, the percentage non-pubescent, pubescent and adolescent in each year of age is shown in Fig. 3 (Ellis, 1948a). The number graded as non-pubescent was found to fall from $100 \%$ at 9.5 years to $50 \%$ at 13.1 years and 0 at 17.5 years; the figures also illustrate the effect of raising the school-leaving age from 14 to 15 years. 'Thus at 14 years
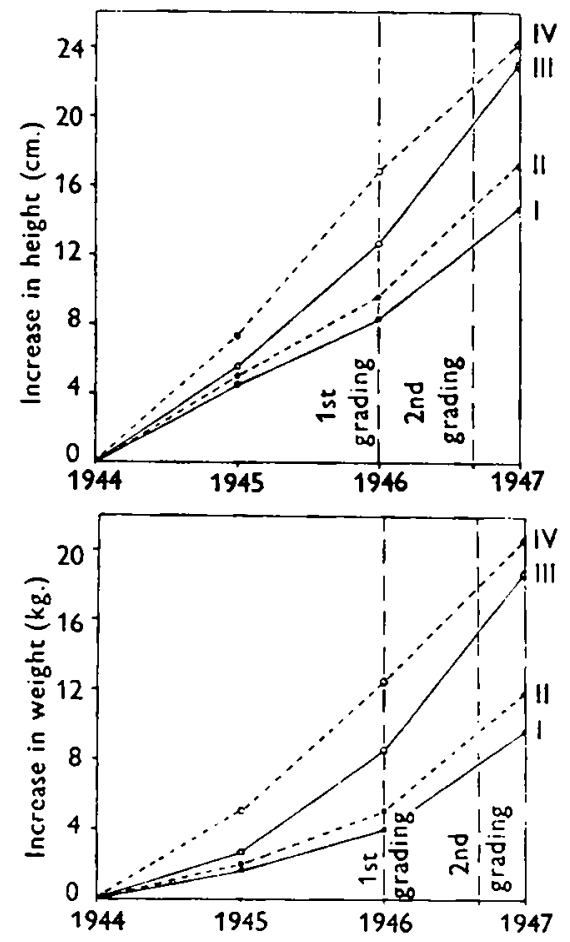

Figs. 4 and 5. Annual height and weight increments of boys in four maturity gradings: I, non-pubescent on first and pubescent on second grading; II, pubescent on first and second grading; III, pubescent on first and adolescent on second grading; IV, adolescent on first and second grading (Ellis, 1948a).

there are as many non-pubescent boys as adolescent, and approximately $40 \%$ of boys are pubescent, whereas at 15 years approximately $60 \%$ of boys have attained adolescence and less than $10 \%$ are non-pubescent. Since each successive phase of maturity is associated not only with differences of growth rhythm, but also of physical performance (Espenschade, 1940; Ellis, 1948b), this has a practical bearing on the composition of groups of boys reaching the labour market, and also on the school-meals service which is now providing for a substantially larger number of boys in whom rate of growth is at a maximum.

In order to assess the rate of growth associated with each successive stage of maturity, boys living in a residential school were graded at the beginning and end of a 9-month period and divided into four groups: (I) those non-pubescent on first and pubescent on second examination; ( 1 ) those pubescent on first and second examination; (3) those pubescent on first and adolescent on second examination and (4) those adolescent on 
first and second examination. The mean annual increments in height and weight of each group were assessed for the 2 years preceding and the year following the first grading. These figures (Figs. 4 and 5 ) and other data included in the same study (Ellis, 1948 a) demonstrate an acceleration of both height and weight increment preceding the clinical manifestations of pubescence and continuing through pubescence, a more rapid gain in both height and weight associated with the passage from pubescence to adolescence and continuing into early adolescence, and subsequent deceleration in height increment noted in older adolescents.

In conclusion, I would like to emphasize again the importance of maturity grading during the growth period, rather than the too rigid concern with chronological age which is evident both in the present Education Act and in the legislation for protection of juveniles in employment. Widdowson (1947) has shown the enormous variation in food consumption of children within the same year-age groups. It would be of great interest to determine whether maturity grading applied to the subjects of such a study would show more consistency in caloric intake in relation to the stage of maturity reached and rate of growth than was revealed by age grouping alone.

\section{REFERENCES}

Abernethy, E. M. (1936). Monogr. Soc. Res. Child. Development, 1, 7 .

Baldwin, B. T. \& Wood, T. D. (1923). Weight-Height-Age Tables for Boys and Girls of School Age. New York: American Child Health Association.

Cawley, R. H., Waterhouse, J. A. H. \& Hogben, H. (1949). Brit. F. soc. Med. 3, 157.

Ellis, R. W. B. (1 946). Arch. Dis. Childh. 21, 181.

Ellis, R. W. B. (1947). Edinb. med. F. 54, 269.

Ellis, R. W. B. (1948a). Arch. Dis. Childh. 23, 17.

Ellis, R. W. B. (1948b). Proc. R. Soc. Med. 4I, I I.

Ellis, R. W. B. (1950). Brit. med. F. i, 85 .

Espenschade, A. (1940). Monogr. Soc. Res. Child Development, 5, I. Serial no. 24.

Greulich, W. W., Dorfman, R. I., Catchpole, H. R., Solomon, C. I. \& Culotta, C. S. (1942). Monogr. Soc. Res. Child Dezelopment, 7, 3. Serial no. 33.

Greulich, W. W. \& Pyle, S. I. (1950). Radiographic Atlas of Skeletal Development of the Hand and Wrist. Stanford, California: University Press.

Hogben, H., Waterhouse, J. A. H. \& Hogben, L. (1948). Brit. F. soc. Med. 2, 29.

Illingworth, R. S., Harvey, C. C. \& Gin, S.-Y. (I949). Lancet, 257, 598.

Meredith, H. V. (1937a). Hum. Biol. 8, 2.

Meredith, H. V. (1937b). Hum. Biol. 8, 279.

Richey, H. G. (1937). Monogr. Soc. Res. Child Development, 2, r. Serial no 8.

Scammon, R. E. (1930). In The Measurement of Man, by Harris, J. A., Jackson, C. M., Paterson, D. G. \& Scammon, R. E. Minneapolis: University of Minnesota Press.

Shuttleworth, F. K. (1 937). Monogr. Soc. Res. Child Development, 2, 5. Serial no. 12.

Shuttleworth, F. K. (1938). Monogr. Soc. Res. Child Development, 3, 5. Serial no. 18.

Simmons, K. (1944). Monogr. Soc. Res. Child Development, 9, 1. Serial no. 37.

Sutcliffe, A. \& Canham, J. W. (1950). The Heights and Weights of Boys and Girls. London: John Murray.

Todd, T. W. (1937). Atlas of Skeletal Maturation. St Louis, Illinois: C. V. Mosby Company.

Wetzel, N. C. (1943). F. Pediat. 22, 329.

Widdowson, E. M. (1947). Spec. Rep. Ser. med. Res. Coun., Lond., no. 257.

Wilson, D. C. \& Sutherland, I. (1949). Brit. med. F. ii, 130.

Woodbury, R. M. (1921). Publ. U.S. Child Bur., Wash., no. 84. 